\title{
Integration of leprosy into general health services in an urban area -a feasibility study *
}

\author{
C R REVANKAR ${ }^{\dagger}$, SAROJ S JHA ${ }^{\ddagger}, V_{\text {V DONGRE }}^{\S}$, \\ S S DESHPANDE ${ }^{\dagger} \&$ R GANAPATI ${ }^{\dagger}$
}

${ }^{\dagger}$ Bombay Leprosy Project, 6/27 Amar Bhuvan, Sion-East, Bombay-400 022, India; $\$$ Preventive and Social Medicine Department, Topiwala National Medical College, Bombay400 008, India; §R.R.E. Society, Acworth Leprosy Hospital, Wadala, Bombay-400 031, India

Received for publication 1 March 1982

Summary To study the feasibility of integrating leprosy treatment into the general health services in Bombay, 198 doctors (essentially private medical practitioners), 120 interns, 32 nurses and 126 other auxiliary health staff were involved in intensive orientation programmes of various types, and doctors were offered a free consultative service and guidance, with a free supply of dapsone. They were encouraged to treat leprosy patients in their own set-up without referring them elsewhere.

After 18 months' follow-up, it was found that 108 doctors (59\%) suspected 771 leprosy cases, of which 724 (94\%) were labelled as leprosy. The investigators confirmed personally 129 of $158(82 \%)$ which were seen by these doctors: $70 \%$ were of tuberculoid type, $6 \%$ were lepromatous and $22 \%$ borderline type. Out of 50 whose skin smears could be taken 25 (50\%) were positive for AFB. At the end of scheme, it was found that $42 \%$ of all cases were under regular treatment.

Short-term follow-up assessment showed that $58 \%$ of doctors treated cases in their clinics as compared to $8 \%$ before study. Similarly the percentage of doctors who referred cases to leprosy clinics or dermatologists was reduced to $42 \%$. Ninety-two per cent of patients expressed their desire to continue treatment from their doctors only. It is concluded that if proper diagnostic guidance and encouragement is given, doctors may be able to manage uncomplicated leprosy cases. Integration is feasible in the urban situation so that leprosy patients get the benefit of health care at the level of 'first contact' with the peripheral service.

\section{Introduction}

Health care in Bombay is organized by public as well as private health units. In public sectors such as municipal services, in addition to medical staff, paramedical staff - nurses, health

*This project was supported under grant-in-aid from the Indian Council of Medical Research, New Delhi, India. 
visitors and medico-social workers - play a very important role. It is the general medical practitioners and specialists who form the private health system. At a most peripheral level of the urban community, the municipal dispensary, doctors and general practitioners and other health staff deliver basic health services of a curative type at a fairly low cost. It is believed that about $60 \%$ of the population in Bombay is cared for by general medical practitioners and that the remainder are dependent on municipal and government systems.

The existing specialized centres for leprosy in Bombay exclusively provide a leprosy service where patients with various difficulties related to their socioeconomic conditions, transport and job problems etc. cannot make full use of such services. A report from the urban areas shows that only $13.1 \%$ of patients registered in urban treatment centres were regular and $86.9 \%$ dropped out. ${ }^{1}$

For urban leprosy control work, it has been recommended that involvement of general medical practitioners and municipal doctors is essential. ${ }^{2}$ However, until recently no such attempt has been made in this direction. The possibilities of involving general medical practitioners in leprosy work through an intensive orientation programme in cities has been reported. ${ }^{3}$ An encouraging result has been reported with integration of leprosy into polyvalent population surveys at a paramedical level. ${ }^{4}$ Such an approach has been favoured by different authors ${ }^{5,6}$ and Horst Buchmann has emphasized that the leprosy control services should be an integral part of primary health care programmes in developing countries. ${ }^{7}$

The present study in Bombay was aimed at finding out the feasibility of such an approach at different levels of health staff, especially at general medical practitioner level, to avoid leprosy cases being referred to specialized leprosy centres or specialists for treatment.

\section{Materials and methods}

A well-defined municipal ward - M (Chembur) - and adjacent small areas of $\mathrm{N}$ ward (Garodia

Table 1. Types of health staff involved

\begin{tabular}{lccccc}
\hline \multicolumn{1}{c}{ Health units } & Doctors & Interns & Nurses & $\begin{array}{c}\text { Laboratory } \\
\text { technicians }\end{array}$ & $\begin{array}{c}\text { Ward boys, } \\
\text { dressers etc. }\end{array}$ \\
\hline $\begin{array}{l}\text { General medical } \\
\text { practitioners }\end{array}$ & $\begin{array}{c}152 \\
(77 \%)\end{array}$ & - & - & - & - \\
$\begin{array}{l}\text { Municipal General Hospital } \\
\text { Municipal dispensaries and }\end{array}$ & 11 & - & 21 & 4 & 72 \\
maternity homes & 13 & - & 8 & 2 & 35 \\
$\begin{array}{l}\text { Central govt health scheme } \\
\text { dispensaries }\end{array}$ & 6 & - & 2 & 1 & 10 \\
$\begin{array}{l}\text { Urban health centre } \\
\text { (medical college) }\end{array}$ & 6 & 120 & 1 & 1 & 1 \\
$\begin{array}{l}\text { Employees State Insurance } \\
\text { Scheme centre (ESIS) }\end{array}$ & 10 & - & - & - & - \\
\hline \multicolumn{1}{c}{ Total staff } & $198 *$ & 120 & 32 & 8 & 118 \\
\hline
\end{tabular}

*21 (11\%) belonged to specialist categories such as dermatology, orthopaedic surgery, paediatrics; 37 (19\%) were ESIS practitioners. $118(60 \%)$ were practising allopathy. The remainder were specialists of ayurved, homeopathy, unani and other systems of medicine. $93(47 \%)$ (both municipal and private sector) were practising in the slum area. The remainder were in the mid and high economic population area. 
Nagar) were adopted as the project area, where the estimated prevalence rate of leprosy was about 10 per 1,000 . The following health units offering curative health services in these areas were included in this study: Municipal General Hospital 1; Municipal dispensaries and maternity homes 10; Urban health centre (attached to municipal teaching medical college) 1; Central Government Health Scheme (CGHS) dispensaries 2; Employees State Insurance Scheme (ESIS) centre 1; General medical practitioners including specialists 250 .

The health staff involved in this scheme are shown in Table 1. Doctors, especially those practising general medicine, were given prime importance as they play a very crucial role in the urban leprosy control programme.

\section{METHODS}

The whole investigation was divided into three phases.

Phase I. Data on initial awareness about leprosy and other existing antileprosy activities were collected by employing a questionnaire technique.

Phase II. All the health staff included in Table 1 were exposed to an intensive orientation programme including refresher courses, group talks with slide shows in the doctors' clinics, individual visits, discussion (including leprosy case demonstrations), and the distribution of various literature such as books, folders, leaflets and posters. Drugs like dapsone, clofazimine and rifampicin were supplied whenever asked for. Doctors were encouraged to treat leprosy

Table 2. Existing leprosy service in different health structures

\begin{tabular}{|c|c|c|c|c|c|}
\hline \multirow[b]{2}{*}{ Health units } & \multicolumn{5}{|c|}{ Number of doctors: } \\
\hline & Contacted & $\begin{array}{c}\text { Suspecting } \\
\text { leprosy } \\
\text { cases }\end{array}$ & $\begin{array}{l}\text { Treating } \\
\text { cases }\end{array}$ & $\begin{array}{l}\text { Referring } \\
\text { cases }\end{array}$ & $\begin{array}{l}\text { Interested } \\
\text { in leprosy }\end{array}$ \\
\hline Municipal General Hospital & 11 & $\begin{array}{c}3 \\
(27 \%)\end{array}$ & 0 & 3 & 3 \\
\hline $\begin{array}{l}\text { Municipal dispensaries and } \\
\text { maternity homes }\end{array}$ & 13 & $\begin{array}{l}10 \\
(77 \%)\end{array}$ & 1 & 1 & 1 \\
\hline Urban health centre & 6 & 0 & 0 & 0 & 2 \\
\hline $\begin{array}{l}\text { Central govt health scheme } \\
\text { dispensaries }\end{array}$ & 6 & $\begin{array}{c}2 \\
(33 \%)\end{array}$ & 0 & 1 & 2 \\
\hline $\begin{array}{l}\text { Employees State Insurance } \\
\text { Scheme centre (ESIS) }\end{array}$ & 10 & $\begin{array}{c}1 \\
(10 \%)\end{array}$ & 0 & $1 \dagger$ & 1 \\
\hline General medical practitioners & 152 & $\begin{array}{l}104 \\
(68 \%)\end{array}$ & 8 & 96 & 143 \\
\hline Total & 198 & $\begin{array}{l}120 \\
(61 \%)\end{array}$ & $\begin{array}{l}9 \\
(8 \%)\end{array}$ & $\begin{array}{l}102 \\
(85 \%)\end{array}$ & $\begin{array}{l}152 \\
(77 \%)\end{array}$ \\
\hline
\end{tabular}

*Due to non-availability of dapsone either on the market or in the municipal schedule (DDS supplied exclusively to specialized centres) even a dermatologist of the Municipal General Hospital had to refer cases to leprosy hospitals.

$\dagger$ In accordance with government rules, ESIS doctors have to refer leprosy patients to leprosy hospitals for certificates and treatment. 
cases in their own clinics without referring them to specialized leprosy centres or to specialists. During this phase, 3 refresher courses, 45 slide shows with group talks and 180 individual discussions were carried out. Facilities for skin smears (AFB), were extended by the project.

Phase III. A short-term follow-up assessment was done by (a) interviewing staff by both direct and indirect methods through questionnaire, and (b) interviewing available leprosy patients through a questionnaire. This assessment was undertaken to determine the acceptability of these services both to the health staff, especially doctors, and to patients.

\section{Results and discussions}

The existing leprosy service in different health units is shown in Table 2.

\section{AWARENESS OF LEPROSY AND THE LEPROSY PROBLEM}

The questionnaire study indicated that $39 \%$ of doctors of all categories scored more than $50 \%$, showing satisfactory leprosy awareness (score 50\% and above was considered as a basis of satisfactory knowledge). The doctors working under urban health centres and CGHS had better knowledge compared to general medical practitioners where, in the latter group, 35 out of $79(44 \%)$ who completed the first questionnaire scored above $50 \%$. Only $23 \%$ of the municipal doctors scored above 50\%, although, of the interns who had recently passed their degree examination, 79 out of $113(67 \%)$ who answered questions showed evidence of satisfactory awareness. Awareness amongst laboratory technicians was much better than among nurses.

After approximately 18 months' follow-up the questionnaire study showed the following findings.

Table 3. Leprosy case detection by the doctors

\begin{tabular}{lccc}
\hline \multicolumn{1}{c}{ Health units } & $\begin{array}{c}\text { No. who } \\
\text { suspected } \\
\text { leprosy cases }\end{array}$ & $\begin{array}{c}\text { No. of cases } \\
\text { suspected }\end{array}$ & $\begin{array}{c}\text { No. of cases } \\
\text { confirmed }\end{array}$ \\
\hline General medical practitioners & 90 & 514 & 478 \\
Municipal General Hospital & 5 & $(67 \%)$ & $(93 \%)$ \\
Municipal dispensaries and & 6 & 141 & 138 \\
maternity homes & 3 & $(18 \%)$ & $(98 \%)$ \\
Central govt health scheme & 2 & $(3 \%)$ & 22 \\
dispensaries & & 24 & $(85 \%)$ \\
Urban health centre & 2 & $(3 \%)$ & 23 \\
& & $6.7 \%)$ & $(96 \%)$ \\
Employees State Insurance & 108 & 60 & 3 \\
Scheme centre (ESIS) & \multicolumn{1}{c}{$\begin{array}{c}(50 \%) \\
\text { Total }\end{array}$} & 771 & 60 \\
& & $(100 \%)$ & $(100 \%)$ \\
\hline
\end{tabular}


Of 184 doctors who could be followed up, 108 (59\%) suspected leprosy in their clinics amongst their clients.

In the Municipal General Hospital and ESIS centres, attending dermatologists confirmed leprosy cases, whereas elsewhere the cases were confirmed either by the investigators or paramedical workers of the scheme or the doctors themselves.

$67 \%$ of the cases were suspected by general medical practitioners.

Of 158 cases suspected mostly by general practitioners, $132(83 \%)$ were seen personally and confirmed as leprosy by the investigating team. A sample of 54 (39\%) of 138 cases already registered for treatment at the Municipal General Hospital were seen and confirmed by this team. This obviously showed that these doctors were quite capable of diagnosing leprosy cases of all types.

$70 \%$ of patients were of tuberculoid type - especially in general medical practitioners' dispensaries; $6 \%$ were of lepromatous type, of which $2 \%$ were detected by general practitioners themselves; $22 \%$ of patients were of borderline type.

Of 664 patients of all types examined $186(28 \%)$ could be verified by the investigating

Table 4. Treatment and management of leprosy cases in the general dispensaries

\begin{tabular}{|c|c|c|c|c|c|c|}
\hline \multirow[b]{2}{*}{ Health units } & \multirow{2}{*}{$\begin{array}{c}\text { No. of } \\
\text { cases } \\
\text { confirmed }\end{array}$} & \multirow{2}{*}{$\begin{array}{l}\text { No. of cases } \\
\text { treated in } \\
\text { doctors' } \\
\text { clinics* }\end{array}$} & \multicolumn{4}{|c|}{ No. of cases referred for treatment } \\
\hline & & & $\begin{array}{l}\text { Leprosy } \\
\text { hospital }^{\dagger}\end{array}$ & $\begin{array}{c}\text { Private } \\
\text { specialists }\end{array}$ & $\begin{array}{l}\text { Municipal } \\
\text { Hospital }\end{array}$ & Total \\
\hline $\begin{array}{l}\text { General medical } \\
\text { practitioners }\end{array}$ & 478 & $\begin{array}{c}178 \\
(37 \%)\end{array}$ & $\begin{array}{l}115 \\
(24 \%)\end{array}$ & $\begin{array}{r}150 末 \\
(31 \%)\end{array}$ & $\begin{array}{l}35 \\
(7 \%)\end{array}$ & $\begin{array}{l}300 \\
(63 \%)\end{array}$ \\
\hline $\begin{array}{l}\text { Municipal General } \\
\text { Hospital }\end{array}$ & 138 & $\begin{array}{c}138 \\
(100 \%)\end{array}$ & - & - & - & - \\
\hline $\begin{array}{l}\text { Municipal } \\
\text { dispensaries and } \\
\text { maternity homes }\end{array}$ & 22 & $\begin{array}{c}5 \\
(23 \%)\end{array}$ & 7 & - & $\begin{array}{c}10 \\
(45 \%)\end{array}$ & $\begin{array}{c}17 \\
(77 \%)\end{array}$ \\
\hline $\begin{array}{l}\text { Central govt health } \\
\text { scheme dispensaries }\end{array}$ & 23 & $\begin{array}{c}21 \\
(91 \%)\end{array}$ & 2 & - & - & $\begin{array}{c}2 \\
(9 \%)\end{array}$ \\
\hline Urban health centre & 3 & $\begin{array}{c}3 \\
(100 \%)\end{array}$ & - & - & - & - \\
\hline ESIS centre & 60 & Nil & $\begin{array}{c}60 \\
(100 \%)\end{array}$ & - & - & $\begin{array}{c}60 \\
(100 \%)\end{array}$ \\
\hline Total & 724 & $\begin{array}{c}345 \\
(48 \%)\end{array}$ & $\begin{array}{c}184 \\
(25 \%)\end{array}$ & $\begin{array}{l}150 \\
(20 \%)\end{array}$ & $\begin{array}{l}45 \\
(6 \%)\end{array}$ & $\begin{array}{c}379 \\
(52 \%)\end{array}$ \\
\hline
\end{tabular}

*Despite regular visits and encouragement, doctors treated only $48 \%$ of the patients in their own clinics.

$\dagger 25 \%$ of the cases were referred to public leprosy hospital. The main reasons for referring $52 \%$ of the patients were for treatment and other complications. Under ESIS, all the patients have to be referred to leprosy hospital for certificates and treatment under existing government rules.

$\$ 31 \%$ of the patients from the general practitioners' group were referred to private specialists such as dermatologists mainly because their group practises especially in non-slum areas. But the comparative picture showed definite changes regarding case detection, referral and treatment in the clinics before and after study. 
team. Among these cases, 4 had plantar ulcers, 6 had grade II hand deformities (clawing) and 2 had grade I hand deformity (WHO grading).

50 patients were subjected to smear examination (lepromatous and borderline types): $25(50 \%)$ were found to be smear positive for AFB; 7 out of $25(54 \%)$ of these cases were attended by general practitioners. (These smears were taken by the paramedical workers of the project.)

Of 70 interns who completed the second questionnaire $46(65 \%)$ said that they detected cases during their field posting. However, further details were not available.

\section{Results of a short-term assessment}

The initial and follow-up questionnaire studies of doctors did not show any difference with reference to their knowledge of leprosy and its problems.

Though 120 interns participated in this scheme, only 70 (58\%) completed the second questionnaire. No significant difference was observed in their knowledge. The third questionnaire, sent by post (as these interns left college), had replies from only 5 interns (4\%) and no additional information could be gathered.

Attractive posters of small size (on leprosy) may be accepted by these doctors. Of 159 doctors $79(50 \%)$ displayed small-size posters announcing 'Treatment available here' in Hindi, but only $11(7 \%)$ of 159 doctors displayed large-size posters.

$29(27 \%)$ of 108 doctors, of whom $23(80 \%)$ were general practitioners, maintained the minimum possible records. The records from the Municipal General Hospital were much better than those from general practitioners. The questionnaire data showed that $88(75 \%)$ of 117 doctors felt that records maintenance was important from the point of view of indicating the regularity of treatment. Unfortunately, however, because they were too busy, those who maintained records did not enter the details of drugs used.

In $60(23 \%)$ out of 264 cases correct addresses were recorded, 34\% (90/264) addresses were wrong, and 43\% (114/264) were not recorded. Proper recording of addresses is essential in urban areas for follow-up cases, a point which was stressed to these doctors.

Though 108 doctors showed their interest either in case detection or treatment, only 20 (19\%) were actually touching patients for examination purpose, the remainder being hesitant to handle them physically for fear of infection. Only $12(13 \%)$ doctors out of 108 were not afraid of leprosy infection.

Table 5. Performance of doctors before and after study

\begin{tabular}{cccc}
\hline Study & $\begin{array}{c}\text { No. who } \\
\text { suspected cases } \dagger\end{array}$ & $\begin{array}{c}\text { No. who } \\
\text { referred cases } \ddagger\end{array}$ & $\begin{array}{c}\text { No. who } \\
\text { treated cases }\end{array}$ \\
\hline Before (198 doctors) & 120 & 102 & 9 \\
After (184 doctors)* & $(60 \%)$ & $(85 \%)$ & $(8 \%)$ \\
& 108 & 45 & 63 \\
& $(59 \%)$ & $(42 \%)$ & $(58 \%)$ \\
\hline
\end{tabular}

*The remaining 14 were not available for follow-up.

$\dagger$ Despite regular visits, an almost equal number of doctors suspected leprosy cases after the study.

$\$$ Percentage of doctors who referred cases significantly reduced.

$\S$ A very high percentage of doctors starting treating leprosy patients in their clinics. This $58 \%$ of doctors were really interested in managing cases in their set up. Of 63 who treated cases in their clinics $39(62 \%)$ were practising allopathy. 
Table 6. Treatment status of leprosy patients in various clinics*

\begin{tabular}{|c|c|c|c|c|}
\hline Health units & Regular ${ }^{\dagger}$ & Irregular & Drop out $\ddagger$ & $\begin{array}{l}\text { Total no. of } \\
\text { cases treated }\end{array}$ \\
\hline General medical practitioners & $\begin{array}{c}111 \\
(62 \%)\end{array}$ & $\begin{array}{c}5 \\
(3 \%)\end{array}$ & $\begin{array}{c}62 \\
(35 \%)\end{array}$ & $\begin{array}{c}178 \\
(100 \%)\end{array}$ \\
\hline Municipal General Hospital & $\begin{array}{c}18 \\
(13 \%)\end{array}$ & 0 & $\begin{array}{l}120 \\
(87 \%)\end{array}$ & $\begin{array}{c}138 \\
(100 \%)\end{array}$ \\
\hline $\begin{array}{l}\text { Municipal dispensaries and } \\
\text { maternity homes }\end{array}$ & $\begin{array}{c}5 \\
(100 \%)\end{array}$ & 0 & 0 & $\begin{array}{c}5 \\
(100 \%)\end{array}$ \\
\hline $\begin{array}{l}\text { Central govt health scheme } \\
\text { dispensaries }\end{array}$ & $\begin{array}{c}10 \\
(48 \%)\end{array}$ & 0 & $\begin{array}{c}11 \\
(52 \%)\end{array}$ & $\begin{array}{c}21 \\
(100 \%)\end{array}$ \\
\hline Urban health centre & 0 & 0 & $\begin{array}{c}3 \\
(100 \%)\end{array}$ & $\begin{array}{c}3 \\
(100 \%)\end{array}$ \\
\hline $\begin{array}{l}\text { Employees State Insurance } \\
\text { Scheme centre (ESIS) }\end{array}$ & 0 & 0 & 0 & 0 \\
\hline Total & $\begin{array}{c}144 \\
(42 \%)\end{array}$ & $\begin{array}{l}5 \\
(1 \%)\end{array}$ & $\begin{array}{l}196 \\
(57 \%)\end{array}$ & $\begin{array}{c}345 \\
(100 \%)\end{array}$ \\
\hline
\end{tabular}

*Though the doctors were told about case holding programme, this was not followed.

$\uparrow 42 \%$ of the patients were regular for treatment, which was judged on the available records at the doctors' clinics. To test the validity of this data, 23 urine samples were collected randomly on a surprise visit and subjected to estimation of urine dapsone/creatinine ratio in a standard laboratory. Out of these, 19 (83\%) samples showed evidence of patients consuming dapsone tablets regularly. This overall rate of $42 \%$ is higher than that reported by others from Bombay. ${ }^{1}$

¥The drop-out rate was high amongst the patients attending a municipal hospital. This was mainly due to the non-availability of dapsone either in the clinics or on the market. However, the overall drop-out rate (57\%) at the end of 2 years, was not high as compared to other figures reported from Bombay. ${ }^{1}$

Of those doctors initially suspecting cases 59 (55\%) were confident of diagnosing and treating cases. However, they did require the help of investigators or specialists for a second opinion before labelling patients as leprosy cases.

$63(58 \%)$ of the 108 doctors were practising in slum areas. This showed that a larger number of doctors in slum areas were seeing cases since slums are well-known for their hyperendemicity.

$103(88 \%)$ of 117 doctors who completed the second questionnaire felt that leprosy cases could be treated in their clinics.

More than $80 \%$ of doctors favoured integration.

$82 \%$ of interns favoured integration; $63(98 \%)$ of 70 interns who completed the second questionnaire expressed their willingness to treat leprosy cases wherever they practised.

Most of the nurses from the Municipal General Hospital who were involved were transferred to other hospitals, and hence, could not be interviewed.

Of 8 laboratory technicians, $5(62 \%)$ scored more than $50 \%$, compared to initial assessment. Though their knowledge and attitude towards leprosy changed, none of the technicians agreed to take skin smears for AFB due to fear of infection. Two technicians from the Municipal General Hospital, despite repeated discussions and demonstrations, refused to take 
skin smears on the grounds of infection, although they routinely handled sputum of patients suffering from pulmonary tuberculosis.

Of 19 dressers and labourers of various municipal dispensaries and the hospital, 16 (84\%) agreed to touch the leprosy patients; 10 (53\%) did not have objections towards the treatment of such cases in their set-up.

Questionnaire study of 62 patients who could be interviewed showed that 57 of 62 (92\%) expressed their willingness to continue their treatment from their family physicians and municipal hospitals for reasons such as short distances for travel, and convenient times.

Only $5(8 \%)$ patients refused to continue treatment as they felt that either they had to pay for treatment or that drugs were not available.

\section{Conclusions}

1. This short-term investigation showed that the general duty doctors, especially general medical practitioners, were quite capable of treating leprosy cases, mostly of uncomplicated types, provided proper diagnostic guidance and encouragement was given them. This could provide patients with services closer to their homes, along with other medical problems at a most peripheral level.

2. Skin smear and perhaps biopsy facilities could greatly augment the treatment services at peripheral level.

3. A regular supply of suitable literature and the running of reorientation programmes would help them to keep in touch with recent aspects of leprosy.

4. Free availability of dapsone in the general dispensaries or market is essential to encourage the doctors to treat leprosy cases.

5. Paramedical staff engaged in other control programmes should also be involved in leprosy work.

6. This short-term study showed that integration is feasible in this urban area. Simple tuberculoid cases could be managed very easily by general duty doctors. The remaining cases, where specialized care is essential, could be referred to specialized centres. This approach would bring down both the cost of the programme and the work-load of the specialized centres.

7. A random sample of patients attending different leprosy centres, family physicians or specialists should be interviewed on a large scale to establish - from the standpoint of the patient - how best to 'deliver' leprosy control and attain maximum compliance.

8. Reorientation of medical education at undergraduate medical student level is essential to create an enduring interest in leprosy.

\section{Acknowledgements}

The investigators are grateful to the following for their kind co-operation: the Co-ordinating Secretary, German Leprosy Relief Association, Madras; the Dean, Topiwala National Medical College, Bombay; the President, RRE Society, Acworth Leprosy Hospital, Bombay; the Director, Lok Seva Sangam, Bombay; Chembur Medicos Club, Bombay; Indian Medical Association, Chembur Branch, Bombay; I/C of the Municipal General Hospital and dispensaries; and ESIS, CGHS Centres, Damien Foundation, India; WHO; SEARO, New Delhi; Central Health Education Bureau, New Delhi; the Leprosy Mission, England; ALERT; GMLF Wardha; Association National Amici dei Lebbrosi Italy; Dr A G Kulkarni, Department of Preventive and Social Medicine, TNM College, Bombay; Mr P R Dewarkar, Mr B K Rao, Mr N S Shinkar, Mr B R Prasad Rao, and the staff of Bombay Leprosy Project. 


\section{References}

1 Koticha KK, Nair PRR. Treatment defaulters in leprosy: a retrospective study of 42,000 cases. Int J Lepr, 1979; 47: 50-5.

2 Operational Guide and Guidelines of Assessment of Leprosy Control Work in India. Govt of India Publication, 1969;61.

3 Nilkanta Rao MS. Assessment of efforts to induce medical practitioners to participate in urban leprosy control programmes. Lepr Rev, 1976; 47: 149-53.

4 Kapoor PL, Joshi GY, Ranade MG, Nilkanta Rao MS, Deodhar NS. Integrated surveys as a tool for early case detection in leprosy control programme. Lepr in India, 1976; 48: 851-60.

5 Schaller KF. Integration of leprosy control into the health centre scheme. Lepr Rev, 1969; 40: 243-8.

6 Antia NH. The people we fail to reach. (Editorial.) Lepr Rev, 1977; 47: 155-7.

7 Buchmann H. Leprosy control services as an integral part of primary health care programmes in developing countries. German Leprosy Relief Association, Wurzburg. W. Germany, 1979;1-79. 